\title{
APPLICATION OF OBLIQUE PHOTOGRAPHY AND GIS TECHNOLOGIES IN THE INTEGRATED CONSERVATION AND DEVELOPMENT OF HISTORIC CITIES IN CHINA \\ PRACTICES IN SHIGATSE, TIBET AND QUANZHOU (ZAYTON), FUJIAN
}

\author{
Wang Tong ${ }^{1}$, Zhou $\mathrm{Li}^{1}$ \\ ${ }^{1}$ Research Center for Heritage Conservation and Urban-Rural Development Institute for Historic and Cultural Cities of National \\ Importance, THUPDI, Qinghe Middle Street, Haidian District, Beijing, P. R. China - (wangtong, zhouli.th)@thupdi.com
}

Commission II, WG II/8

KEY WORDS: Historic Cities, Integrated Conservation, GIS, Oblique Photography, Height Control, Urban Planning

\begin{abstract}
:
Historic city, as the human settlement space developed in the earliest stage of a city, is the area that best demonstrates the profound cultural significance and urban spatial characteristics of a city. It is also an important and complex type in the field of international cultural heritage conservation. With China's rapid urbanization in the last 30 years, large numbers of Chinese cities are becoming victims of urban problems. Both urban managers and researchers in related fields are well aware that urban development in the new era needs to be coped with from the perspective of leveraging existing stocks. The historic areas of a city make up a valuable stock of land in the city and an important spatial resource. A series of research topics arise in its wake: how to best preserve the characteristics of their historic layout, and avoid losing their identity; how to present its distinctive style with meticulous care; and how to make up for their deficiencies in infrastructure, public service, and environmental quality etc., while stimulating and evoking pride from city managers and the people in their historic city. The application of three-dimensional oblique photogrammetry and GIS technology in historical cities has provided more intuitive graphic support, more accurate spatial positioning, and more convenient data query and statistics for the conservation and development of historical cities. These not only facilitate better research, planning and design for professionals, but also assists city managers to make more adequate decisions.
\end{abstract}

\section{OVERVIEW OF THE PRESERVATION MANAGEMENT SYSTEM OF HISTORIC CITIES IN CHINA}

\subsection{Preservation Management Regulations and Preservation Plan of Historic Cities}

Historic cities are formed during a long period of time, through dynamic interactions of social, economic, cultural, natural and customary forces. Apart from performing basic functions as cities, they also embody outstanding historic and cultural values of the human civilization. Historic cities in China are preserved through a specific program called "Historic and Cultural Cities". Well-preserved historic cities are usually developed under the influence of primitive worship, Confucian rituals, Confucian philosophy of Song and Ming dynasties, or local ethnic beliefs. Surviving long history, their settings in relation to mountains, rivers or unique geographic conditions still speaks volume of the traditional Chinese town planning philosophies.

The concept of "Historic and Cultural Cities" was first raised by the "Law on the Protection of Culture Relics of the People's Republic of China" enacted in 1982, with specific articles on their legal protection. The legal system of the preservation of historic cities consists of two laws and one regulation. Two laws refer to "Law on the Protection of Culture Relics" mentioned earlier, and "Urban and Rural Planning Law". They are the parent laws of the preservation of historic cities in China. One regulation refers to "Regulations on Protecting Historical Famous Towns and Villages". It has been over 30 years since the legal protection of historic cities came into force. Currently there are 135 cities under 7 different categories listed as "National Historic and Cultural Cities".

In recent years, with the development of international heritage preservation theories and the change in social and economic conditions in Chinese cities, preservation practices and methodologies of historic cities have also witnessed some key changes: the focus of the field has broadened from preserving isolated sites to systematic preservation of the whole historic settings, from tangible heritage to both tangible and intangible heritage, from authenticity to both authenticity and integrity, from passive preservation to preventive preservation and appropriate use of heritage sites, from material preservation to cultural revitalization.

Chinese cities are now entering a different stage of urbanization: developable spaces are becoming increasingly limited, funding sources need to be diversified, and the quality of urban life needs to be improved. However, there are still many historic cities with unsatisfying living environment. At the same time, with a large amount of "stock land", historic cities are also easy prey of the capital market. Therefore, it has become a increasingly important topic for historic cities as how to fully execute strict management and control regulations, provide guidance for development, and carry out appropriate use in heritage sites.

Making Preservation plans for "Historic and Cultural Cities" is an important part of the preservation system of historic cities. The plan is a legal document, which puts into practice the 
requirements of the parent laws and regulations, and also serves as a technical guidance for city administrators to implement plans.

\subsection{The Framework of Preservation Plan}

The preservation plan of "Historic and Cultural Cities" needs to be drafted by planning and design institutions of the highest qualifications in China. The plan needs to be reviewed multiple times, going through the review of the municipal government, local expert, city council and municipal planning committee, examined by provincial government, and finally reviewed by experts organized through the department responsible for "Historic and Cultural Cities" in the State Council, during which stakeholders and the general public can submit suggestions, before it can be publicly notified and published as a consensus document. The plan is of great significance and must go through rigorous review.

After years of development, the framework of the preservation plan of "Historic and Cultural Cities" is now complete. In the "Code of conservation planning for historic cities" published this year, it is specified that preservation plan shall cover the following aspects: research of values and characteristics, preservation sites and preservation measures, preservation boundaries and regulations, guarantee of implementation and execution of plans, public safety, etc. The implementation of dynamic heritage resources management measures like HUL (Historic Urban Landscape) in the preservation of Chinese historic cities is of great importance. It makes it possible to use preservation plan as a tool to management and regulate all factors that influence the characteristics of a historic city, including terrain, topography or natural features of cultural significances in a historic city, historic and modern builtenviornment, as well as land-use patterns and spatial arrangement.

In drafting preservation plans, defining values and characteristics of historic cities is a crucial step that will guide the rest of the planning process. Values and characteristics include the Outstanding Universal Value of historic cities and the physical fabric that embodies those values. They also include the settings of the city and its interdependent relationship with mountains and rivers, as well as its traditional spatial arrangement and historic characteristics. As a result, in formulating the regulations for future development, preservation plan needs to take into consideration of the spatial and vertical characteristics of historic cities, as well as the ecological and cultural influences as reflected on the urban landscape. It is especially crucial in deciding on the height limit and the regulation of townscape in both built-up area and new districts. Regulations set by preservation plans are the preconditions that must be followed in the ensuing development activities and city governance process. City administrators are responsible for carrying out the regulations step by step. The part in preservation plan on the guarantee of implementation and recent project points out the projects that need to be implemented in the near future in order to push forward the development of the city. It also specified the required financial support and the mechanisms to carry out the plan. In actual planning, this part will be discussed and studied in great depth, which also invites new technological tools to facilitate the problem-solving process.

\subsection{Research Question}

"Regulations on Protecting Historical Famous Towns and Villages" requires that "Historic and Cultural Cities" must complete preservation plans within a year after being listed. However, after the plan's completion, it usually takes years, sometimes a decade, for it to be enacted. The reason lies in the subjectivity of the planning analysis that makes its conclusions and strategies controversial.

For example, the analyses of heritage values needs to be based on rigorous historic and geographic research, yet historic records and local chronicles before 20th century in China are mostly literary descriptions. The lack of drawings with accurate geometric proportion of Chinese cities makes the interpretation of the written document largely subjective. The earliest satellite image was taken in the 1960 s, so the spatial change of cities before this threshold of time can only be inferred from a few archaeological findings. The absence of spatial reference in historical records makes the value analysis of historic cities less compelling.

In terms of controlling new development in historic cities, height limit is usually the focus of negotiation among preservation institutions, city administrators and developers, because building height is directly linked to the scale of development. The demands of stakeholders differ greatly. As a result, the lack of a unified system to quantify different types of requirement makes it hard for different stakeholders to reach an agreement.

In terms of the execution of plans and decision-making of a development project, decision-makers usually need help of realistic images to visualize the final result in order to make the decision. Currently, renderings made by designers are most commonly used as visual aid, yet they are more often than not far from the reality and out of touch with actual needs of the stakeholders.

\section{APPLICATION OF THREE-DIMENSIONAL OBLIQUE PHOTOGRAPHY AND GIS TECHNOLOGIES}

Introducing three-dimensional oblique photography and GIS technologies into preservation planning process will greatly improve the reliability of planning decisions and provide better visualization of the analysis process as well as the final result. In the preservation planning of Shigatse and Zayton, threedimensional oblique photography and GIS technologies played indispensible roles. This paper will elaborate in the following three aspects.

\subsection{Research of Heritage Values}

The city of Shigatse is a listed "National Historic and Cultural City" located in Tibet, on the west plateau of China, nested between the Himalaya and the Gangdise mountains. The region is crisscrossed by mountains and rivers, with drastic change in altitudes, bearing distinct characters of an agricultural city of plateau ecological environment. Shigatse is also historically the seat of Panchen Lama. Municipal government (tib. rdzong) that holds administrative power and the Temple that holds religious power are the two forces that formed the historic city. The spatial and functional arrangement of the city clearly exhibits this bi-polar power dynamic, creating a unique urban landscape of plateau ecology that reflects the unity of religion and politics. 
With the help of GIS technologies, we are able to compare topographical data in the city of Shigatse with surrounding cities. The result clearly shows that Shigatse has the longest section of the Himalaya Mountains, and is the region with most peaks over 8000 meters in the world. The difference in altitude in the region can be as much as 7000 meters, which produces diverse ecological zones and vegetation types include subtropical evergreen forest, subalpine scrubland and meadow, Alpine steppe and winter lichen. Yarlung Zangbo River flowing east to west across the city also results in a fertile ground, which makes Shigatse the largest arable land in Tibet. Based on these facts, we defined the value and characteristics of Shigatse as being "the ridge of snow-covered plateau, and the Granary of Tibet".

The development and urban landscape of Shigatse are greatly influenced by the local district (tib. rdzong) system, estate (tib. gzhis ka) system and Tibetan Buddhism. Using GIS topography to analyze the distribution of districts, estates and Tibetan Buddhist temples in Shigatse region, it is clearly shown that the historic city area of Shigatse (Samzhubzê District) is the place where the three elements are most concentrated. The spatial arrangement of the core historic district of Shigatse still retains typical characteristics of Tibetan cities, consisting of the fort (rdzong), the town (zhol) and Buddhist temples. It shows that traditional planning of Tibetan cities is influenced by both secular and religious powers, with the fort being the secular center and the temple being the religious center.

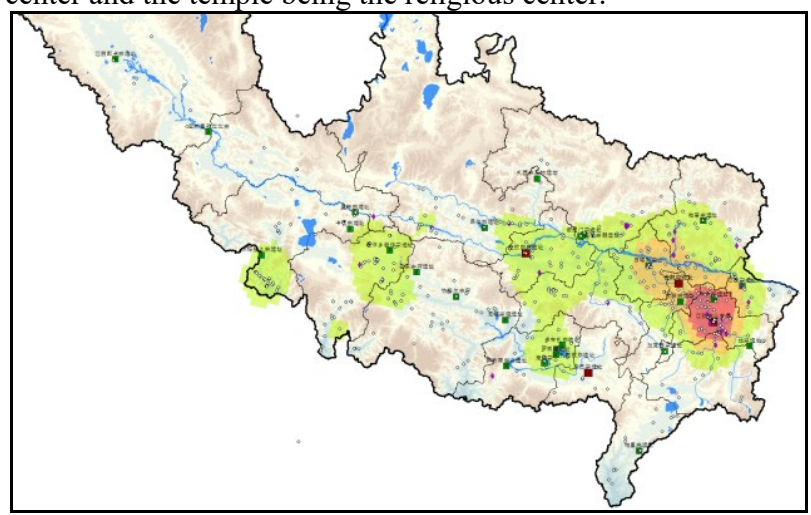

Figure 1. GIS analysis of the distribution density of districts, temples and estates in Shigatse region

Shigatse city is at the intersection of many cultural routes. It is a gateway to central Asia, linking the central Tibetan to Ali and Xinjiang. It is also a gateway to southern Asia, leading to Ladakh, Nepal, India, Bhutan and other countries. However, historic records usually lack geographic reference, and Chinese historic maps only illustrate relative spatial relationships rather than actual distance and routes. As a result, the accuracy of these records and the interpretation of historic documents remains a topic that requires further research. Using GIS analysis to overlay topography with religious and ethnic heritage sites, it is clear that the distribution of cultural heritage sites corresponds with main regional transportation routes, including the Gyirong valley, Zhangmu valley, Rongxar Valley, Gama valley, Chentang Valley and Yadong valley.

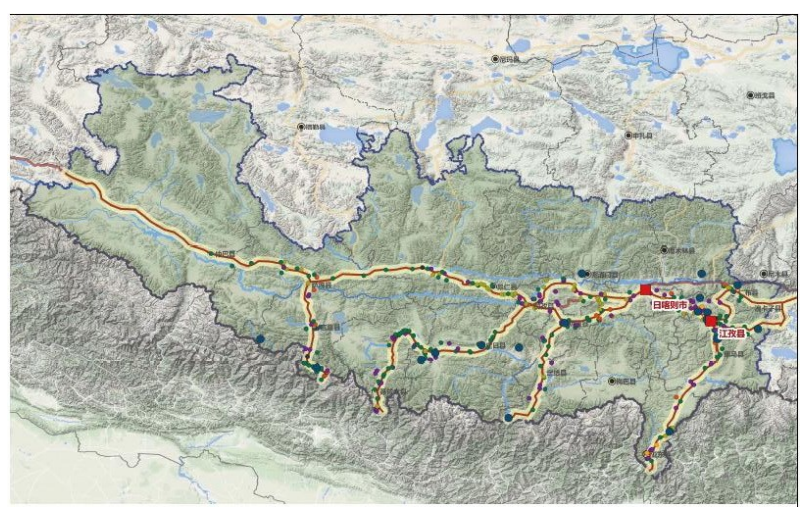

Figure 2. GIS analysis of the cultural routes in Shigatse Region and Cultural Resources along the routes

\subsection{Regulations of townscape and spatial features}

\subsubsection{Height Control of Shigatse City}

As mentioned above, the settings of historic cities and its spatial relationship with geographic features including mountains and rivers are at the core of the preservation and management. In terms of the historic city of Shigatse, the historic boundary of the city and spatial reference points are set by Tashilhunpo Monastery, Samdrubtse Dzong Fort, and the summer Palace of Penchen Lama, as well as the mountains around the cities that has gained cultural significance. The geographic settings and historic sites form 10 visual corridors, including Mount DzongMount Xiari, Mount Dzong-Mount Scorpion, Mount DzongMount Naisangri, Tashilhunpo Monastery-Mount Scorpion, Tashilhunpo Monastery-Mount Xiari, Tashilhunpo MonasterySummer Palace-Mount Naisangri, Tashilhunpo MonasteryMount Dzong, Summer Palace-Mount Dzong, Summer PalaceMount Xiari, Mount Xiari-Mount Scorpion.

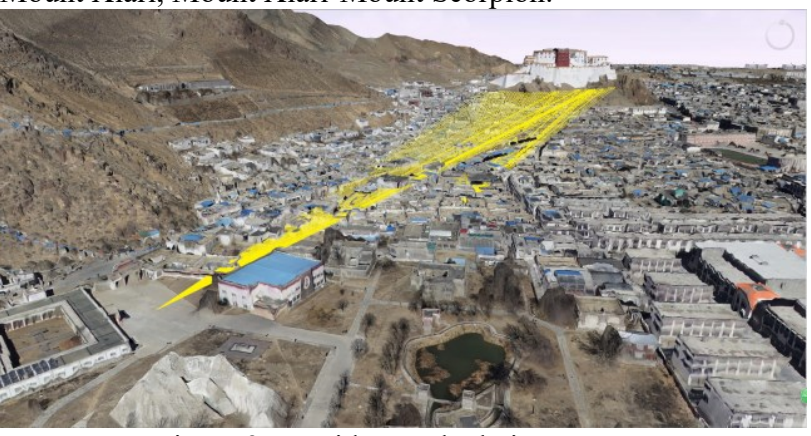

Figure 3. Corridors Calculation process

Traditionally, height control in preservation planning largely relies on perception of the built environment and experience. With the help of 3D oblique photography, spatial models can be generated to go through GIS analysis. it is therefore possible to accurately compute height control parameters of different visual points, and also directly perceive from the model if the sight will be blocked. Because the historic area is generally of low height, while landmarks are located on high grounds, it is not practical to rely solely on visual corridor analysis to set height limits. There is a large room for higher development. The result is clearly shown through images. This also avoids the possibility that different levels of city administrators and different groups of people base the decision of height limits on their own spatial perceptions and lead to a wrong conclusion. 


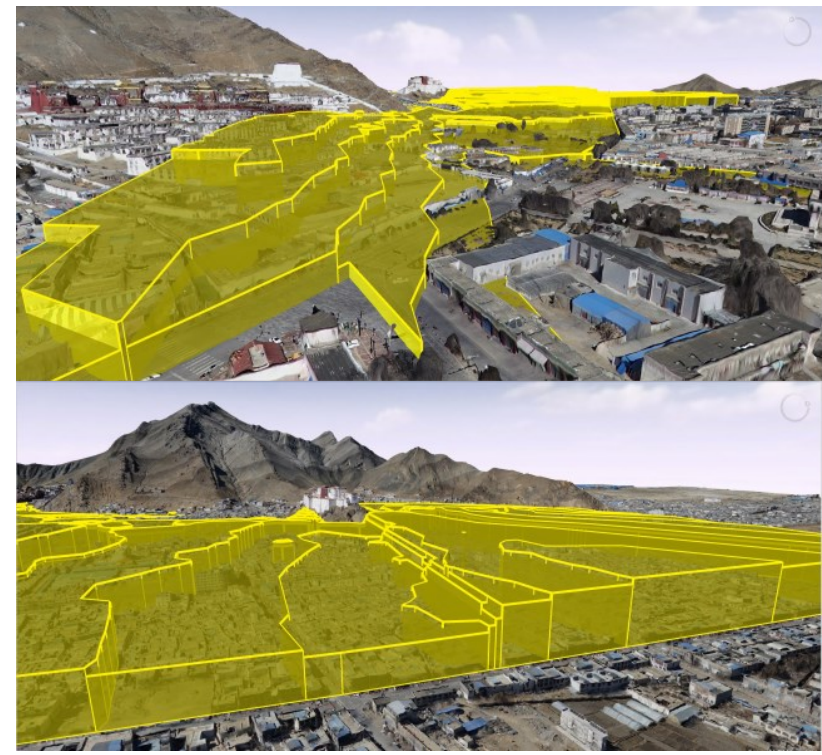

Figure 4. Historic area is generally of low height, while landmarks are located on high grounds, it is not practical to rely solely on visual corridor analysis to set height limits.

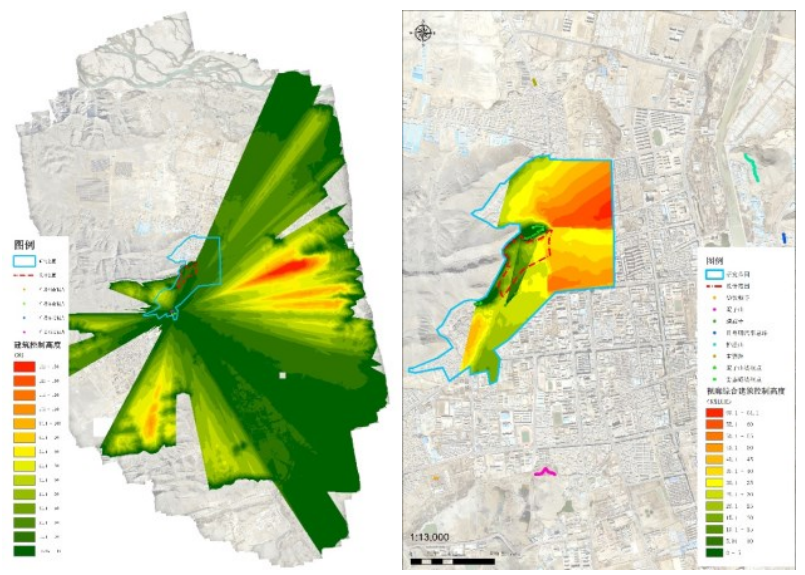

Figure 5. Height control requirement analysis of Shigatse historic city using GIS

\subsubsection{Height control strategy in Zayton}

The height control of Zayton has three goals: first, preserving the integrity of the historic city and its historic settings; second, sustain the perceivable relationship with mountains and rivers; third, highlight its role as a landmark site along the world heritage "maritime silk road". Preserving the relationship with mountains and rivers is the hardest to quantify among the three in drafting height control regulations. As a result, we introduced GIS tools to research into this specific topic. To begin with, we broke down the question as follows:

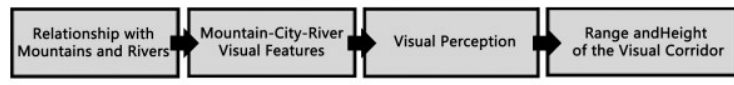

Figure 6. Illustration of decomposing the problem

The relationship with mountains and rivers is in essence the spatial perception of the mountain, the city and the river through specific visual corridors. In the project, we chose public landmarks as viewing points, and delineate the range of these visual corridors by drawing tangent lines to these landmarks.

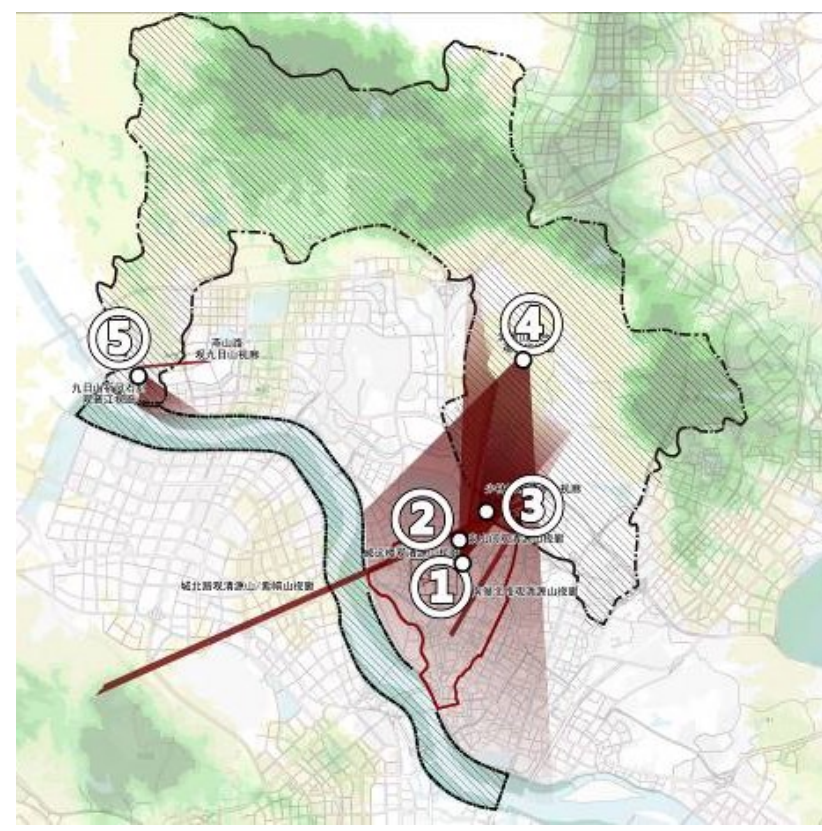

Figure 7. Range of the visual corridor

\begin{tabular}{|c|c|c|}
\hline No. & & Visual Corridors \\
\hline (1) & $\begin{array}{l}\text { From } \\
\text { Weiyuan } \\
\text { House } \\
\text { viewing } \\
\text { Qinyuan } \\
\text { Mountain }\end{array}$ & $\begin{array}{l}\text { Viewing from the second floor on } \\
\text { Weiyuan House, drawing tangent } \\
\text { lines cutting the edge of the trees as } \\
\text { shown in the survey photo and the } \\
230 \text {-meter contour line of Qinyuan } \\
\text { mountain The range of the visual } \\
\text { corridor is set by the projection of the } \\
\text { three 3D lines onto the plane. (about } \\
1 / 3 \text { of the mountain body is in sight) }\end{array}$ \\
\hline (2) & $\begin{array}{l}\text { From } \\
\text { Quanshan } \\
\text { Gate viewing } \\
\text { Qinyuan } \\
\text { Mountain }\end{array}$ & $\begin{array}{l}\text { Drawing tangent lines from Quanshan } \\
\text { Gate to } 300 \text {-meter contour line of } \\
\text { Qinyuan Mountain. The range of the } \\
\text { visual corridor is set by the projection } \\
\text { of the three 3D lines onto the plane. } \\
\text { (about } 1 / 3 \text { of the mountain body is in } \\
\text { sight) }\end{array}$ \\
\hline (3) & $\begin{array}{l}\text { From Shaolin } \\
\text { Road } \\
\text { viewing } \\
\text { Qinyuan } \\
\text { Mountain }\end{array}$ & $\begin{array}{l}\text { Viewing from the intersection of } \\
\text { Shaolin Road, Chengbei Road and } \\
\text { Wenling North road toward northeast, } \\
\text { drawing tangent lines to the } 300 \text {-meter } \\
\text { contour line of Qinyuan Mountain. } \\
\text { The range of the visual corridor is set } \\
\text { by the projection of the four 3D lines } \\
\text { onto the plane. (about } 1 / 3 \text { of the } \\
\text { mountain body is in sight) }\end{array}$ \\
\hline (4) & $\begin{array}{l}\text { From Nantai } \\
\text { Rock in } \\
\text { Qinyuan } \\
\text { Mountain } \\
\text { viewing } \\
\text { Jinjiang } \\
\text { River }\end{array}$ & $\begin{array}{l}\text { Viewing from Nantai Rock in } \\
\text { Qinyuan Mountain towards the } \\
\text { historic city, making tangent lines } \\
\text { cutting the outer boundary of East } \\
\text { West lake, and the shoreline of } \\
\text { Jinjiang river. The range of the visual } \\
\text { corridor is set by the projection of the } \\
\text { two tangent lines and the shoreline of } \\
\text { Jinjiang river onto the plane. }\end{array}$ \\
\hline
\end{tabular}




\begin{tabular}{l|l|l|} 
From Qi & $\begin{array}{l}\text { Viewing from the carved stone tablet } \\
\text { on the observation platform toward }\end{array}$ \\
Feng Carved & $\begin{array}{l}\text { Stone in Jiuri } \\
\text { Mountain } \\
\text { viewingiang River. The range of the visual } \\
\text { Jinjing River }\end{array}$ & $\begin{array}{l}\text { corridor is set by the projection of the } \\
\text { three 3D lines onto the plane. }\end{array}$
\end{tabular}

Table 1. Description of the Range of Visual Corridors

Using GIS calculations, we are able to generate the optimal height limit in ideal circumstances.

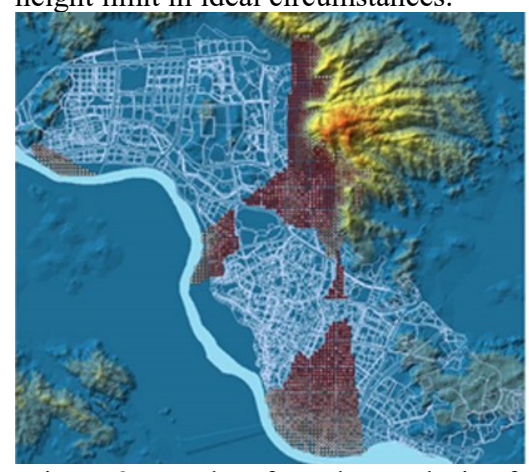

$$
\begin{aligned}
& \text { Results of Overlay Analysis } \\
& \text { Height Limit } \\
& \text { c }<12 \text { meters } \\
& \text { 12-24 meters } \\
& \text { 24-48 meters } \\
& \text { - 48-60 meters } \\
& \text { 60-100 meters } \\
& \text { - } 2100 \text { meters }
\end{aligned}
$$

Figure 8. Results of overlay analysis of visual corridors (Wang Tong, Jiang Ying, Luo Wen, 2016)

However, the result contradicts with specifications of existing regulatory plans (equivalent of zoning laws in the US). Comparing development land requirements with the result of visual corridor analysis, we found that implementing the optimal height control will lead to the reduction of building height on 426 hectares of land. In these areas, future development scale will be severely reduced.
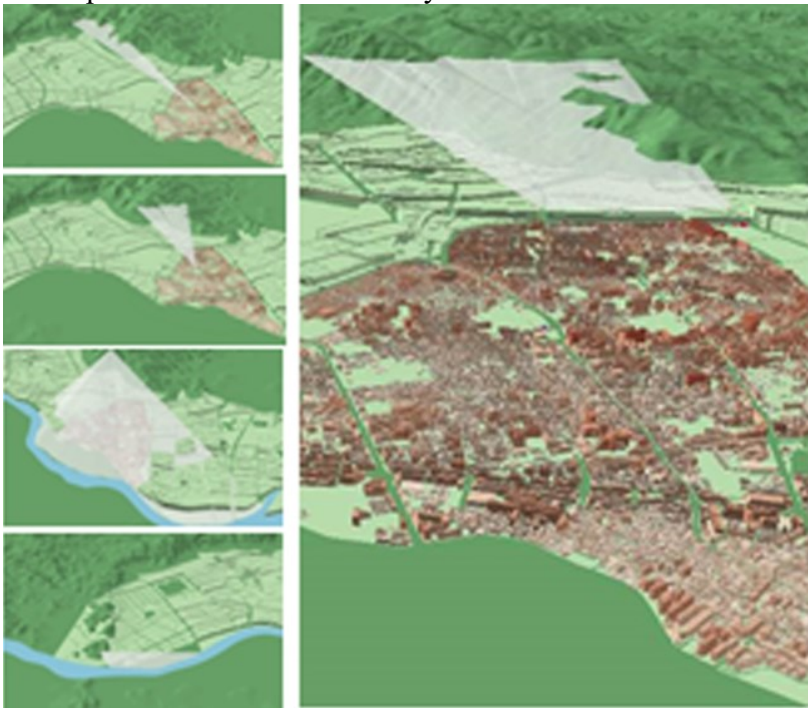

Figure 9. Corridors Calculation process of overlaying current development conditions and existing regulatory plans (Wang Tong, Jiang Ying, Luo Wen, 2016)

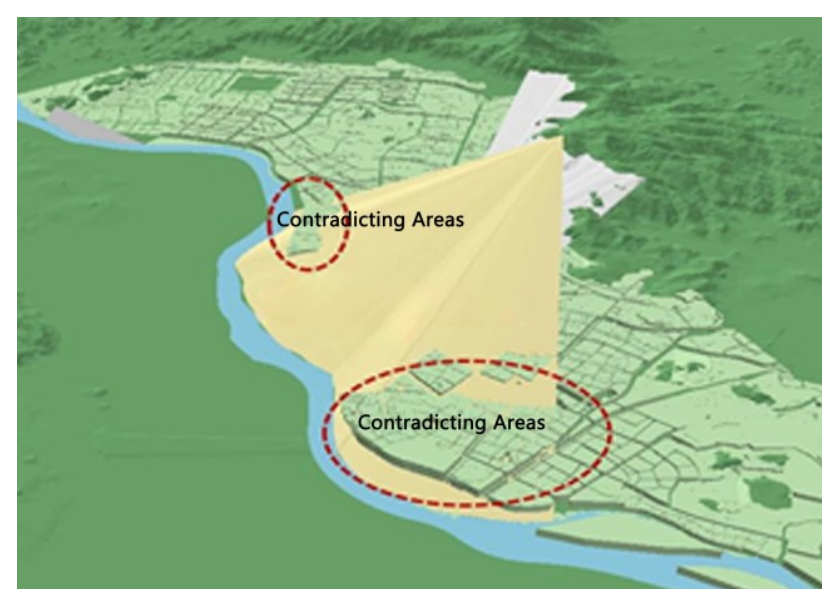

Figure 10. Contradicting Areas (Wang Tong, Jiang Ying, Luo Wen, 2016)

In order to resolve the contradictions between the result of visual analysis and existing regulations, the plan designates the contradicting areas as "sensitive area", so that it can be regulated through a more flexible mechanism. More specifically, an expert review board will be formed to discuss every single case in this area, with the result of GIS calculations as a reference. It will allow high-rises if it does not block the skyline. The final plan combines quantitative and qualitative analyses, using both rigid and flexible regulative measures to control height.

\subsection{Decision-making in Development Projects}

In Shigatse project, place-making is the focus of the plan that needs to be implemented in the near future. Public places provide people an opportunity to experience the unique characteristics of a city, interact with each other, forming dynamic spaces in historic cities.

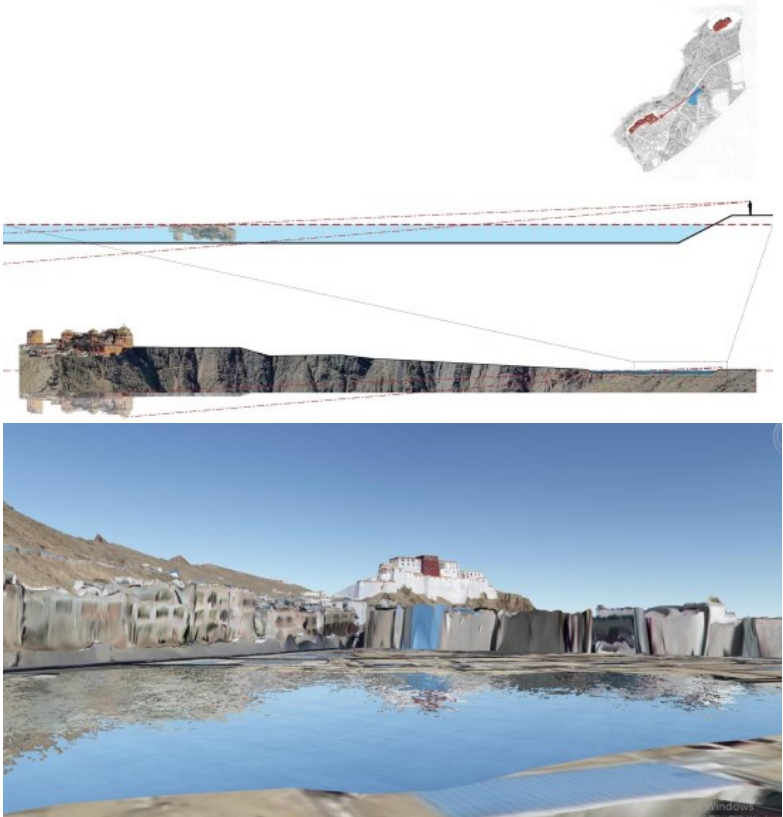

Figure 11. 3D oblique photography of current conditions overlay with simulated water body planned (1)

We chose a water catchment area of a natural gully to create a waterfront space. There are successful cases in other Tibetan cities, the artificial lake of the Potala Palace square, for instance. Waterfront space in Shigatse is not only a mere copy 
of those in other cities. The satellite image from 1960s shows that there was historically a body of water in this location, and was later filled in for construction. Therefore creating an artificial lake at its original place is in accordance with preservation principals of historic cities, and also technically feasible.
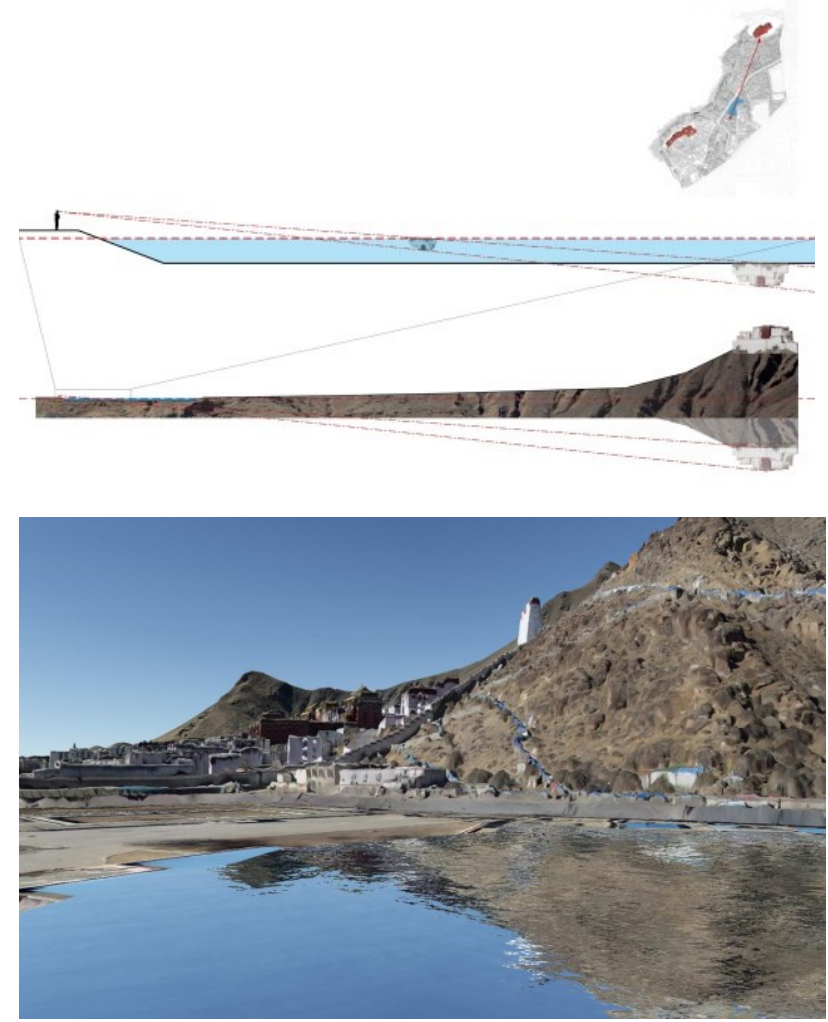

Figure 12. 3D oblique photography of current conditions overlay with simulated water body planned (2)

The source of water is the melted snow and ice on the plateau. The water is clear enough to reflect surrounding landscape. The core of the design is to fully reflect the Tashilhunpo Monastery and Samdrubtse Dzong Fort on the water surface. We used 3D oblique photography to aid design. After importing the designed water body into the model, the result of reflection can be simulated, overlaid by current conditions. By adjusting the area and shape of the water surface and comparing different combinations, we managed to enable visitors to enjoy a full reflection in multiple different angles. With the help of technology, this decision-making process can be easily explained to our client and the general public. Even nonprofessionals with limited experience of spatial design can quickly understand the intended result. In comparison with graphic analysis, 3D tools greatly improve the accuracy of information delivery and the efficiency of communication, and are of great help in the decision-making process of the project.

\section{CONCLUSIONS AND PROSPECTS}

3D oblique photography and GIS technologies can be widely applied in the preservation of the landscape and settings of historic cities. These tools can help us record urban space in a large scale, discovering topographical relationships between the past and the present, providing scientific support in the analysis of heritage values. The powerful spatial analysis functions of these tools help to quantify specific problems, so as to avoid subjectivity in the analysis. Visual simulations can provide an accurate projection of the results, facilitating the decisionmaking process in planning and development. In the future, as 3R technology, big data and open-source database become increasingly commonplace, the application of 3D oblique photography and GIS technologies can also be extended to play a more important role in the preservation of historic cities and urban development.

However, technologies are useful tools to improve efficiency, but they cannot replace human being in the aesthetic evaluation and collaborative effort to find the optimal solution. After all, the charm of historic cities lies in the traditional way of life passed down from generation to generation through the course of history; in the shared understanding of the importance of preservation and active engagement of municipal affairs; in the diversity and creativity born endlessly from historic spaces. Historic cities are so much more than "correct", rational and quantifiable spaces.

\section{REFERENCES}

Han, S., Peng, Z., 2001. Application of GIS in Urban Planning Abroad. Foreign Urban Planning, pp. 42-44.

Mayor of London, 2012. London View Management Framework. London. pp. 1-283.

Song, X., Niu, X., 2013. Geographic Information Systems Internship Course. Beijing: Science Press, pp. 1-395.

Tong, Z., 2009. Research on GIS Model of Building Height Control Based on Line of Sight. National Architectural Digital Technology Teaching Seminar Proceedings, pp. 5.

Wang, T., Jiang, Y., Luo, W., 2016. Construction of Height Control System from the Perspective of Landscape protection. Annual Conference on Urban Planning in China, pp. 13. 